○ Open Access Full Text Article

ORIGINAL RESEARCH

\title{
Investigation of Preoperative Traction Followed by Percutaneous Kyphoplasty Combined with Percutaneous Cement Discoplasty for the Treatment of Severe Thoracolumbar Osteoporotic Vertebral Compression Fractures
}

\author{
You-Di Xue* \\ Zhao-Chuan Zhang* \\ Wei-Xiang Dai \\ Department of Orthopaedics, Xuzhou \\ Central Hospital, Xuzhou, Jiangsu \\ Province, People's Republic of China \\ *These authors contributed equally to \\ this work
}

\begin{abstract}
Objective: To evaluate the feasibility, clinical efficacy and imaging results of preoperative traction (PT) followed by percutaneous kyphoplasty (PKP) combined with percutaneous cement discoplasty (PCD) for treating severe thoracolumbar osteoporotic vertebral compression fractures (OVCFs).
\end{abstract}

Methods: A total of 13 patients with severe thoracolumbar OVCFs treated by PT followed by PKP combined with PCD were enrolled. General information, PT time, operation time, postoperative hospital stay, perioperative complications, visual analog scale (VAS) score, Oswestry disability index (ODI) score, local kyphosis angle, intervertebral angle (IVA), anterior vertebral height $(\mathrm{AVH})$ and posterior vertebral height $(\mathrm{PVH})$ were recorded.

Results: The average VAS score at admission was $7.4 \pm 3.5$, decreased to $4.3 \pm 1.7$ after PT and $2.3 \pm 0.7$ three days after operation, and $1.5 \pm 0.9$ at last follow-up. The average ODI score was $73.7 \pm 21.4$ before operation, decreased to $26.6 \pm 9.3$ three days after operation and 13.7 \pm 7.1 at last follow-up. Compared to VAS and ODI scores at admission, these at the third day after operation and last follow-up were significantly different. At admission, the IVA was $3.4^{\circ} \pm 6.8^{\circ}$, the disc height was $5.7 \pm 1.2 \mathrm{~mm}$, the AVH was $10.7 \pm 3.2 \mathrm{~mm}$, and the PVH was $25.7 \pm 4.2 \mathrm{~mm}$, which, after PT, changed to $8.1^{\circ} \pm 7.3^{\circ}, 8.6 \pm 2.6 \mathrm{~mm}, 18.5 \pm 2.8 \mathrm{~mm}$, and 26.2 $\pm 7.1 \mathrm{~mm}$, respectively, and the differences were significant. The average kyphotic angle was $43.4^{\circ} \pm 17.8^{\circ}$ at admission, and decreased to $26.3^{\circ} \pm 6.7^{\circ}$ after PT, $17.5^{\circ} \pm 8.4^{\circ}$ three days after operation and $19.1^{\circ} \pm 10.3^{\circ}$ at last follow-up, and the differences were significant.

Conclusion: PT followed by PKP combined with PCD for the treatment of severe thoracolumbar OVCFs was an effective and simple procedure with satisfactory short-term clinical outcomes by relieving pain and improving kyphosis.

Keywords: osteoporosis, spinal fracture, kyphosis, traction, percutaneous kyphoplasty, percutaneous cement discoplasty

\section{Introduction}

Osteoporotic vertebral compression fractures (OVCFs) are the most common pathological fractures caused by osteoporosis. The thoracolumbar segment under greater pressure is located between the rigid thoracic vertebrae and the lumbar vertebrae with a large range of motion, and is the most likely site for spinal 
fractures. ${ }^{1}$ Clinically, severe OVCFs or continuous multisegmental OVCFs usually occur at the thoracolumbar junction, leading to kyphosis. Secondary kyphosis often causes a series of problems, such as local pressure concentration, fatigue and pain, and adjacent vertebrae fractures. ${ }^{2,3}$ For this, surgical treatment is usually required to relieve symptoms and improve kyphosis.

Traditional open surgery not only requires osteotomy to correct kyphosis but also requires extended segmental fixation and/or bone cement reinforcement to improve fixation strength, leading to increased hospitalization costs and complications. ${ }^{4}$ Percutaneous kyphoplasty (PKP) has a direct effect on the stabilization and pain relief of the fractured vertebrae, with the advantages of minor trauma and early ambulation, but its roles in correcting kyphosis are poor and the incidence of bone cement leakage during the treatment of severe OVCFs and kyphosis is high. ${ }^{5,6}$ For OVCFs with disc and endplate injury, PKP cannot effectively relieve pain and prevent the aggravation of kyphosis, and thus it might not be an effective method to treat severe OVCFs with kyphosis. ${ }^{7}$ As an emerging minimally invasive surgery, percutaneous cement discoplasty (PCD) has achieved satisfactory clinical results in the treatment of discogenic pain in the elderly and correction of degenerative scoliosis, which has aroused strong people's attention and has gradually been used in clinical practice. ${ }^{8-10}$

In the treatment of severe spinal deformity, preoperative traction (PT) can effectively reduce the degree of deformity and the difficulty of operation. ${ }^{11-13}$ PT can loosen the contracture of the muscles and ligaments around the fractured vertebral body, partially restore the height of the vertebral body, increase the intervertebral space and the intervertebral angle, thereby improving the kyphosis. In addition, PT, as a simple and practical measure for the treatment of cervical spondylosis and lumbar disc herniation syndrome, can effectively relieve symptoms, reduce the use of drugs, and delay or even avoid surgery. ${ }^{14-18}$

In order to make up for the deficiency of open surgery and PKP in the treatment of severe thoracolumbar OVCFs, PT followed by PKP combined with PCD was used to treat severe thoracolumbar OVCFs. We performed this retrospective analysis of 13 cases with severe thoracolumbar OVCFs treated by PT followed by PKP combined with PCD to evaluate the feasibility, clinical efficacy and imaging results of this treatment method.

\section{Materials and Methods}

This study was conducted in accordance with the declaration of Helsinki. This study was conducted with approval from the Ethics Committee of Xuzhou Central Hospital. Written informed consent was obtained from the participants or their family members.

\section{Subjects}

From September 2017 to October 2019, 20 cases of severe thoracolumbar OVCFs with kyphosis were treated in our department. All patients received the treatment of PT followed by PKP combined with PCD. Thirteen cases with complete follow-up data and the follow-up time of more than 12 months were retrospectively analyzed. Of the 13 cases, 5 were males and 8 were females, with an average age of 71.3 years old. Six patients had no obvious history of trauma and 7 patients had a history of minor trauma, which were caused by a fall for 3 cases and lifting heavy objects for 4 cases, with an average ill course of 15.5 days (2-70 days). All patients had at least one vertebral compression fracture in the range of T10-L3, the compression rate was more than $75 \%$, and grade 3 of Genant Classification. ${ }^{19}$ The bone mineral density (BMD) was measured by dual-energy X-ray absorptiometry (DXA). The baseline demographics of the patients are shown in Table 1.

Surgical indications: (1) osteoporosis was diagnosed by DXA BMD (T value $\leq-2.5$ ); (2) OVCFs in the T10-L3 segment with compression rate more than $75 \%$, and grade 3 of Genant Classification, ${ }^{19}$ were identified as fresh fracture or fracture nonunions by MRI; (3) pathological fractures caused by other diseases, such as tumor, hematological diseases, inflammation, etc., were excluded.

\section{PT}

All patients were treated with lumbar traction firstly after admission to hospital. The traction weight was about onefifth of the body weight, and a soft pillow was placed at the top of the kyphosis to maintain a mild hyperextension position. The bedside X-ray was performed every three days, and the timing of surgery was determined by the effects of traction. The traction procedure generally lasted for 3-6 days. The traction method is shown in Figure 1.

\section{Evaluation Index}

The baseline parameters, clinical outcomes and imaging results of the patients were recorded. 
Table I Summary of Demographics in 13 Patients with OVCFs and Kyphosis at Thoracolumbar Spine

\begin{tabular}{|c|c|c|c|c|c|c|c|c|}
\hline $\begin{array}{l}\text { Patient } \\
\text { Number }\end{array}$ & $\begin{array}{c}\text { Genderl } \\
\text { Age }\end{array}$ & $\begin{array}{c}\text { Disease } \\
\text { Course } \\
\text { (Days) }\end{array}$ & $\begin{array}{c}\text { Fracture } \\
\text { Level }\end{array}$ & $\begin{array}{c}\text { BMD } \\
\text { (T-Value/g/ } \\
\mathrm{cm} 2 \text { ) }\end{array}$ & $\begin{array}{c}\text { Traction } \\
\text { Duration } \\
\text { (Days) }\end{array}$ & $\begin{array}{l}\text { Operation } \\
\text { Duration } \\
\text { (Minutes) }\end{array}$ & $\begin{array}{c}\text { Stay of } \\
\text { Hospital } \\
\text { (Days) }\end{array}$ & $\begin{array}{c}\text { Follow-Up } \\
\text { Duration } \\
\text { (Months) }\end{array}$ \\
\hline I & $M / 73 y$ & 2 & TIO-II & $-2.6 / 0.703$ & 3 & 60 & 8 & 13 \\
\hline 2 & $M / 69 y$ & 3 & TIO & $-3.4 / 0.642$ & 7 & 105 & 10 & 18 \\
\hline 3 & $M / 81 y$ & 11 & TII-12 & $-2.5 / 0.712$ & 5 & 85 & 9 & 20 \\
\hline 4 & $M / 7 l y$ & 33 & TII & $-2.8 / 0.672$ & 4 & 75 & 11 & 16 \\
\hline 5 & $M / 76 y$ & 3 & $\mathrm{~T} 12$ & $-2.8 / 0.672$ & 5 & 65 & 15 & 15 \\
\hline 6 & F/6ly & 6 & LI & $-3.1 / 0.621$ & 9 & 60 & 10 & 17 \\
\hline 7 & F/65y & 7 & TI2-LI & $-4.0 / 0.0 .634$ & 8 & 75 & 14 & 23 \\
\hline 8 & F/77y & 70 & TI2-LI & $-3.6 / 0.613$ & 6 & 80 & 13 & 21 \\
\hline 9 & $F / 72 y$ & 15 & LI-2 & $-2.9 / 0.703$ & 7 & 100 & 16 & 14 \\
\hline 10 & $F / 65 y$ & 15 & LI & $-2.7 / 0.793$ & 6 & 95 & 12 & 13 \\
\hline II & $F / 69 y$ & 4 & L2 & $-3.3 / 0.633$ & 5 & 90 & 14 & 16 \\
\hline 12 & F/78y & 8 & LI-2 & $-2.8 / 0.672$ & 4 & 85 & 11 & 18 \\
\hline 13 & F/70y & 25 & L2 & $-2.6 / 0.703$ & 6 & 70 & 9 & 15 \\
\hline
\end{tabular}

Abbreviations: M, male; F, female; y, years old; OVCFs, osteoporosis vertebral compression fractures; BMD, bone mineral density.

The baseline parameters included sex, ages, duration of symptoms, PT time, operation time, postoperative hospital stay and complications.

Clinical outcomes: the visual analog scale (VAS) scores and Oswestry disability index (ODI) scores were recorded on admission, three days after operation and at the last follow-up.

Imaging results: BMD was measured by DXA. Magnetic resonance imaging (MRI) was performed before operation to confirm the diagnosis. X-ray and two-dimensional computed tomography scans (2D-CT) examination of thoracolumbar segment and the whole spine. 2D-CT were performed before operation, three days after operation and at the last follow-up. The local kyphosis angle, the vertebral wedge angle, intervertebral angle (IVA), the anterior vertebral height (AVH) and posterior vertebral height $(\mathrm{PVH})$ were recorded on admission, after traction, and at the last follow-up. The distribution of bone cement in vertebral body and inter-vertebral disc was observed.

\section{Surgical Procedure}

All operations were performed under general anesthesia. The patients took a prone position and the operating bed

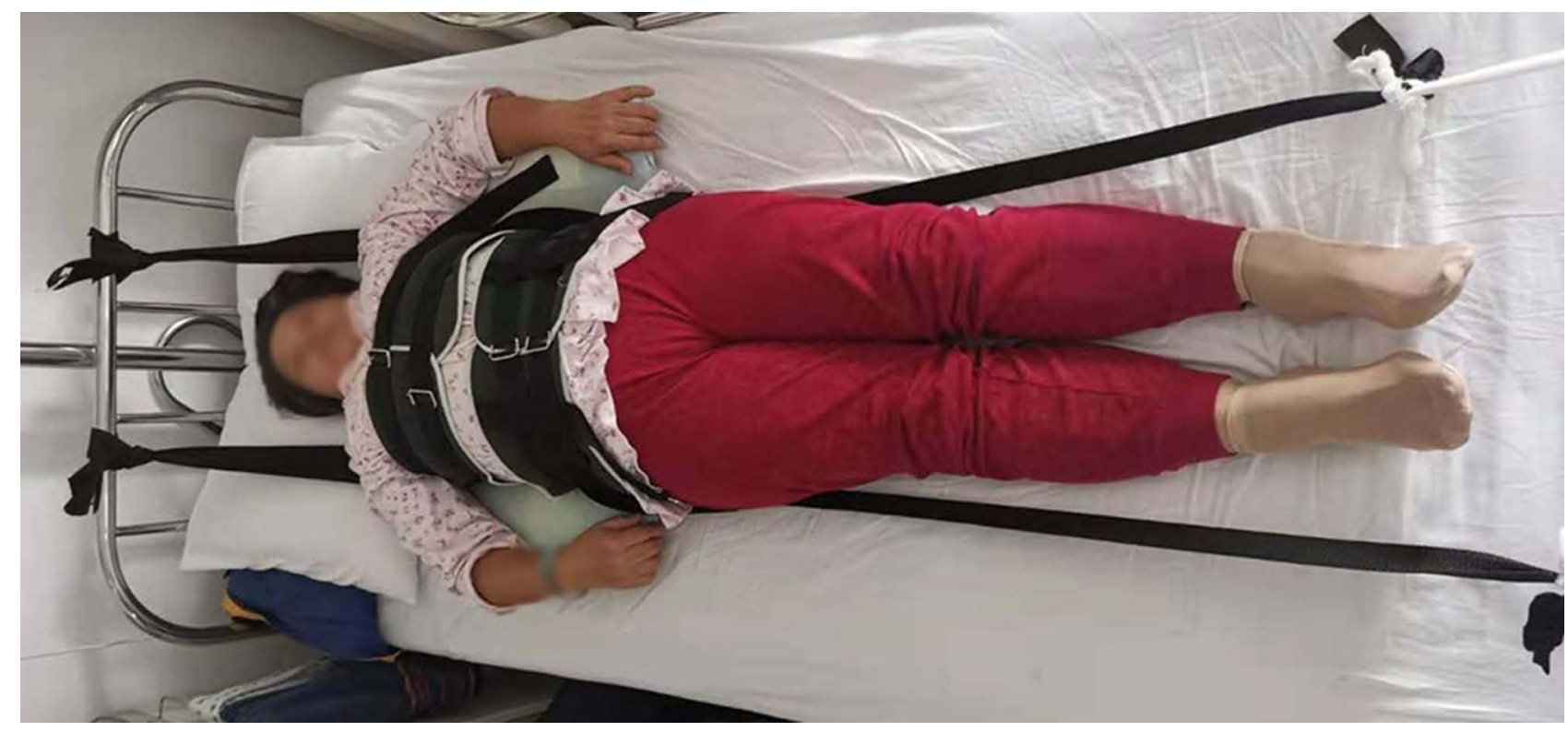

Figure I Preoperative traction (PT) using lumbar traction apparatus for the treatment of severe thoracolumbar osteoporotic vertebral compression fractures (OVCFs). 
was adjusted to make the thoracolumbar segment in a mild hyperextension. For the cases refractory to the postural reduction and traction, intraoperative traction using traction bed under general anesthesia was performed (Figure 2).

The extrapedicular approach was used for all cases, and we adopted the approach introduced by Song Wang et al to perform percutaneous intervertebral bridging cementoplasty. ${ }^{20}$

Firstly, the fractured vertebrae was punctured, the distance and angle between the needle tip and the midline was confirmed by the cross-section CT imaging. The puncture was performed using extrapedicular approach to keep the puncture needle in the center of the vertebral body and make it stop at the anterior cortex of the vertebral body. Then, the balloon was implanted into the vertebral body and dilated, and the cement was injected.

Secondly, the working channel was shifted cranially, the puncture needle was inserted into the upper intervertebral space through the upper endplate and aimed at the anterior part of the inter-vertebral space. Then, the cement was injected into the space. Meanwhile, the channel was moved back to the vertebral body, allowing the cement to connect the disc space with the body.

Thirdly, the working channel was shifted caudally, the puncture needle was inserted into the lower intervertebral space through the endplate, and aimed at the anterior part of the inter-vertebral space. Then, the cement was injected into the space. Meanwhile, the channel was moved back to the vertebral body, allowing the cement to connect the disc space with the body.

Last but not least, the adjacent upper and lower vertebral space of the injured vertebrae were accomplished with percutaneous vertebroplasty by the extrapedicular approach.

\section{Results}

All 13 patients were followed up for 13 to 23 months, with an average follow-up of 16.84 months, and the complete data was obtained. No serious complications occurred during the perioperative period. The average time of PT was 6 days (3-9 days), the average operation time was $75.3 \pm 21.4$ minutes (60-105 minutes), and the average hospital stay was 11 days (8-16 days). The average VAS score was $7.4 \pm 3.5$ on admission, decreased to $4.3 \pm 1.7$ after traction, to $2.3 \pm 0.7$ three days after operation, and to 1.5 \pm 0.9 at the last follow-up. The average ODI score was 73.7 \pm 21.4 before operation, decreased to $26.6 \pm 9.3$ three days after operation, and to $13.7 \pm 7.1$ at the last follow-up. Compared with those on admission, there were significant differences in VAS score and ODI score three days after operation and at the last follow-up $(P<0.05)$.

Compared with those on admission, after traction, the IVA changed from $3.4^{\circ} \pm 6.8^{\circ}$ to $8.1 \pm 7.3^{\circ}$, the disc height changed from $5.7 \pm 1.2 \mathrm{~mm}$ to $8.6 \pm 2.6 \mathrm{~mm}$, the AVH changed from $10.7 \pm 3.2 \mathrm{~mm}$ to $18.5 \pm 2.8 \mathrm{~mm}$, and the PVH changed from $25.7 \pm 4.2 \mathrm{~mm}$ to $26.2 \pm 7.1 \mathrm{~mm}$. There were significant differences in IVA, the disc height, AVH and PVH between on admission and after traction $(P<0.05)$ (Table 2$)$.

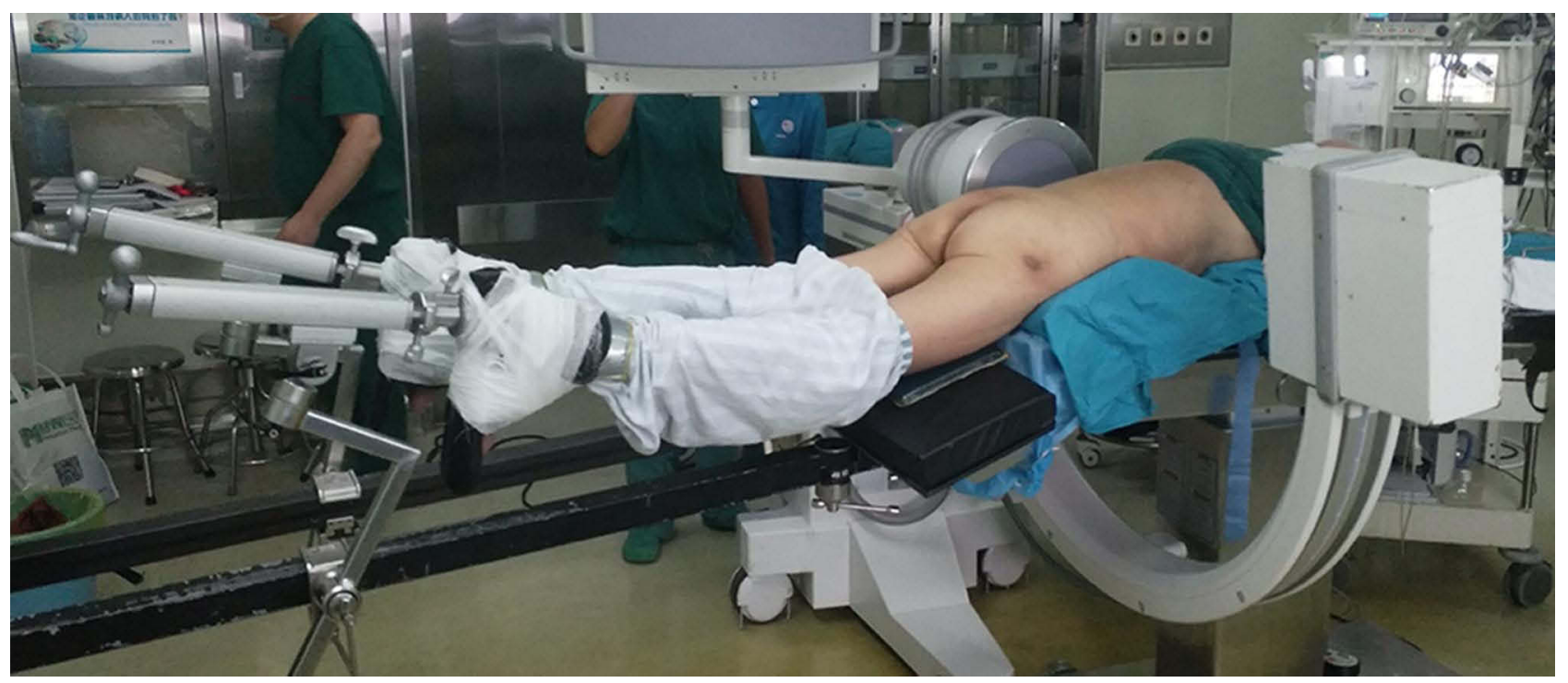

Figure 2 Intraoperative traction using traction bed under general anesthesia for the case refractory to the postural reduction and preoperative traction (PT). 
Table 2 Imaging Outcomes in 13 Patients at Admission and After Traction

\begin{tabular}{|l|l|l|l|l|l|}
\hline & Kyphotic Angle & IVA & Disc Height & AVH & PVH \\
\hline At admission & $43.4 \pm 17.8$ & $3.4 \pm 6.8$ & $5.7 \pm 1.2$ & $10.7 \pm 3.2$ & $25.7 \pm 4.2$ \\
After traction & $26.3 \pm 6.7^{*}$ & $8.1 \pm 7.3^{*}$ & $8.6 \pm 2.6^{*}$ & $18.5 \pm 2.8^{*}$ & $26.2 \pm 7.1$ \\
\hline
\end{tabular}

Note: *Compared with those at admission, using paired $t$-tested, $\mathrm{P}<0.05$.

Abbreviations: IVA, intervertebral angle; AVH, anterior vertebral height; $\mathrm{PVH}$, posterior vertebral height.

On admission, the average kyphotic angle was $43.4^{\circ}$ $\pm 17.8^{\circ}$, decreased to $26.3^{\circ} \pm 6.7^{\circ}$ after traction, to $17.5^{\circ}$ $\pm 8.4^{\circ}$ three days after operation, and to $19.1^{\circ} \pm 10.3^{\circ}$ at the last follow-up. Compared with that on admission, there were significant differences in the kyphotic angle after traction, three days after operation and at the last follow-up $(P<0.05)$ (Table 3). A typical case is shown in Figure 3.

\section{Discussion}

Thoracolumbar junction is located between the lumbar vertebrae with high range of motion and the stiff thoracic vertebrae, where the pressure is most concentrated, and thus it is the most common site of spinal fracture. It is reported that most of OVCFs occurs in the thoracolumbar spine ${ }^{6}$ and it is also not rare that multiple vertebral fractures occur simultaneously. In this area, consecutive multiple vertebral compression fractures or severe compression fracture of a single vertebral body inevitably lead to local kyphosis. The kyphosis not only increases the probability of adjacent vertebral fracture but also brings a series of problems, such as muscle fatigue, chronic low back pain, indigestion, shorter height, etc.

Due to the difficulty of operation and the high rate of the cement leakage, it has been considered that severe OVCFs with kyphosis is a relative contraindication for PVP and PKP. ${ }^{21,22}$ With the advancement of puncture technologies, many scholars have applied PVP or PKP to this special type of fracture. However, although PVP or PKP can relieve the pain caused by fracture, it cannot correct the secondary kyphosis, let alone complications caused by kyphosis, such as muscle fatigue, chronic pain, and so on. ${ }^{23-25}$ Additionally, some studies suggest that, OVCFs, like vertebral fractures caused by trauma, are often complicated with intervertebral disc and cartilage endplate injuries. If these complicated injuries are ignored, postoperative pain symptoms cannot be completely relieved, and the kyphosis would be gradually aggravated due to the cartilage endplate and intervertebral disc injuries, which cannot be prevented by vertebroplasty. ${ }^{20,26}$ In addition to minimally invasive treatment, some scholars use osteotomy and internal fixation to fix compressed fractures and correct kyphosis. In order to improve fixing strength, long-segment fixing or cement-enhanced screws are required. However, this surgical approach is highly traumatic and expensive, and the incidence of perioperative complications is also very high.

PCD was first proposed by Varga in 2014 for the treatment of low back pain caused by degeneration of lumbar intervertebral disc in the elderly, with satisfactory clinical effects. ${ }^{8}$ In recent years, some scholars have utilized this method to treat the degenerative diseases of lumbar and achieved good clinical outcomes. ${ }^{9,10}$ Since 2015, Song Wang et $\mathrm{al}^{20}$ have used percutaneous intervertebral bridging cementoplasty (PIBC) to treat thoracolumbar adjacent multi-segmental vertebral compression fractures with intervertebral disc-endplate complex injury. Through the bridging effect of bone cement, the compressed vertebral body and the injured intervertebral disc-endplate complex are fixed together to achieve the purpose of analgesia and stabilization of the vertebral body. After an average of 29.9 months of

Table 3 Clinical and Imaging Outcomes in I 3 Patients at Admission, After Traction, 3 Days After Operation and at the Last Follow Up

\begin{tabular}{|l|l|c|c|c|}
\hline & At Admission & After Traction & 3 Days After Operation & Last Follow-Up \\
\hline VAS & $7.4 \pm 3.5$ & $4.3 \pm 1.7^{*}$ & $2.3 \pm 0.7^{*}$ & $1.5 \pm 0.9^{*}$ \\
ODI & $73.7 \pm 21.4$ & N/A & $26.6 \pm 9.3^{*}$ & $13.7 \pm 7.1^{*}$ \\
Kyphotic angle $\left(^{\circ}\right)$ & $43.4 \pm 17.8$ & $26.3 \pm 6.7^{*}$ & $17.5 \pm 8.4^{*}$ & $19.1 \pm 10.3^{*}$ \\
\hline
\end{tabular}

Note: *Compared with those at admission, using paired $t$-tested, $\mathrm{P}<0.05$.

Abbreviations: VAS, visual analog scale; ODI, Oswestry disability index. 
A

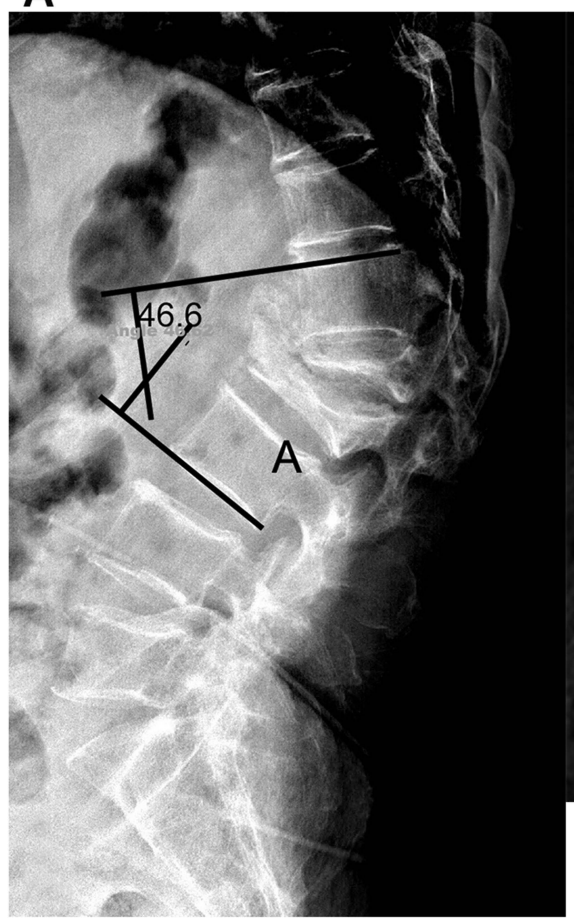

D

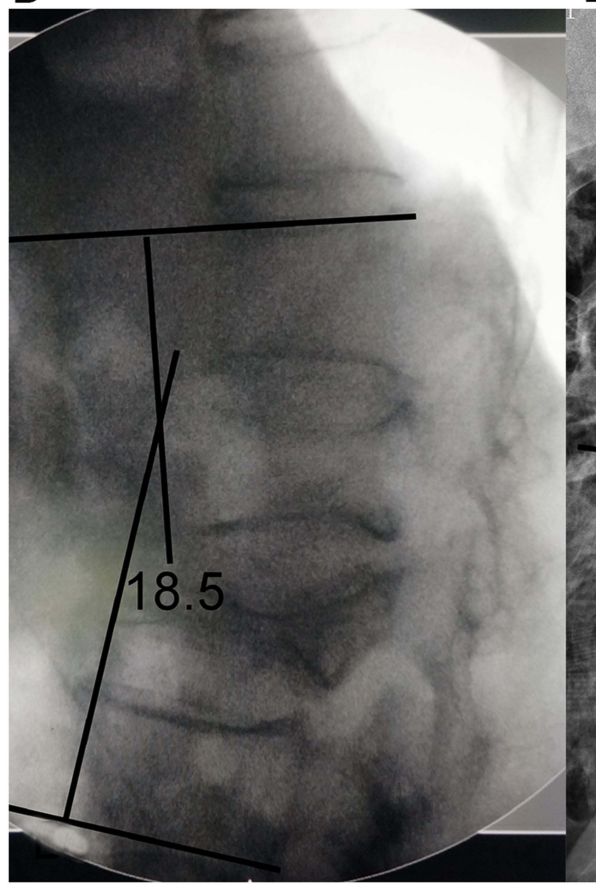

B

\section{C}

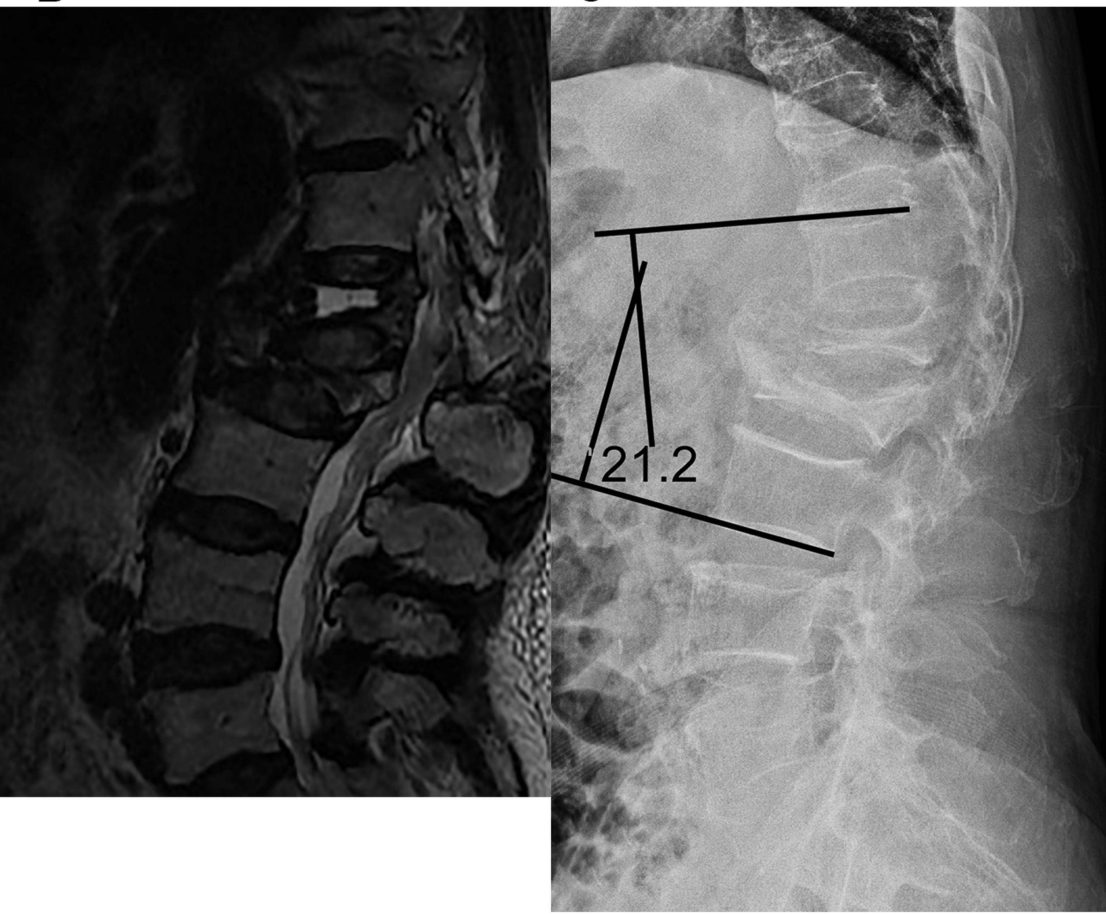

E

F

Figure 3 A 72-years old female with severe osteoporotic vertebral compression fractures (OVCFs) and kyphosis at LI-2 treated with preoperative traction (PT) followed by percutaneous kyphoplasty (PKP) combined with percutaneous cement discoplasty (PCD). (A) Lateral X-ray at admission demonstrated LI-2 severe OVCFs, and the local kyphosis angle was $46.6^{\circ}$; (B) magnetic resonance imaging (MRI) at admission showed severe compressed and subacute fracture of $\mathrm{LI}-2$, with effusion formation in the $\mathrm{LI}$ body; (C) After traction of 6 days, the lateral X-ray showed the disc height was increased and the local kyphosis angle was decreased to $21.2^{\circ}$; (D) After intraoperative traction using traction bed under general anesthesia, the fluoroscopic image showed the disc height was increased, the height of LI vertebral body was restored, and the local kyphosis angle was decreased to $18.5^{\circ}$; (E) After operation, the lateral X-ray showed the bone cement leakage at intervertebral foramen and in front of the intervertebral space, the local kyphosis angle was $10.7^{\circ}$; (F) two-dimensional computed tomography scans (2D-CT) at the final follow up duration showed the local kyphosis angle was $12.0^{\circ}$, and the bone cement maintain at the original position. 
clinical follow-up, none of 32 cases experienced bone cement displacement and fracture, and they obtained lasting fixation strength of the fixed segments, which indicated that PIBC was an effective minimally invasive method for the treatment of continuous multi-segmental compression fractures of thoracolumbar vertebrae.

Lumbar traction has been widely used in the treatment of lumbar disc herniation and spinal deformity. In the treatment of lumbar disc herniation, lumbar traction expands the intervertebral space by tightening the structures such as intervertebral disc fibrous annulus and ligament to reduce the pressure on the nerve roots. In the treatment of spinal deformity, traction is usually used to do the preoperative preparation. For the stiffness of deformity, strong traction is usually required. For example, various types of bone traction are needed to reduce deformities, thereby reducing the difficulty and risk of the final orthopedic operation. In this study, all patients underwent lumbar traction before operation, and their spines were placed in an overextended position with a soft pillow on the top of kyphosis to restore vertebral height and reduce kyphosis. ${ }^{27}$ At the same time, bedside X-ray examination was conducted every 3 days to confirm the effect of traction. The kyphosis and vertebral height were partially corrected after traction in all patients. Among them, 9 patients significantly improved the height of the compression vertebral body, while the other 4 patients did not. For the 4 cases, although there was no significant change in the height of the vertebral body before and after traction, the height of intervertebral space significantly increased, and the intervertebral angle was significantly improved, which is of positive significance for the improvement of kyphosis.

In this study, all 13 patients were followed up for more than 1 year. The VAS scores and ODI scores of all patients were significantly improved after operation and at the last follow-up, and there were no serious complications. The results of imaging examination showed that the thoracolumbar kyphosis was significantly improved, compared with that before operation, and the local kyphosis angle did not increase significantly at the last follow-up. A comprehensive approach was used to treat severe thoracolumbar OVCFs with kyphosis for all patients. First of all, preoperative hyperextension traction could partially restore the height of compressed vertebral body, and opened the deformed intervertebral disc complex and anterior longitudinal ligament, partially restored height of the narrowed intervertebral space, and improved the angle of intervertebral kyphosis, even becoming lordosis. The restoration of vertebral height combined with the change of intervertebral space can reduce the degree of local kyphosis, thereby reducing the difficulty of operation and restoring the physiological curvature of the spine. During the operation, the compressed vertebral body was further expanded by balloon, and then bone cement was implanted in the intervertebral space and vertebral body, which could effectively relieve pain caused by fracture and kyphosis. The bone cement bridged the disc space and vertebral body could effectively maintain the supporting effect of the anterior column, and the long-term effect was satisfactory.

Bone cement leakage is the most common complication of PKP, and various consequences caused by the leakage have been widely reported in the literature. ${ }^{6,28}$ However, there are few literatures on the leakage of bone cement caused by PCD. On the one hand, the number of related literatures about PCD are quite limited and no literatures on bone cement leakage have been found; on the other hand, the compact and intact annulus fibrosus around the intervertebral disc can effectively avoid the leakage of bone cement. However, in this study, the incidence of cement leakage in the intervertebral space was higher $(7,21)$, and it mainly occurred in front of the intervertebral space. Continuous hyperextension traction before surgery could release the contracture annulus or even the anterior longitudinal ligament in front of the intervertebral disc, which could effectively relieve kyphosis, but it might lead to fissures in the anterior annulus. When PCD was performed, bone cement was likely to leak from the anterior fissures. However, further clinical follow-up observations are still needed to confirm whether such leakage does any harm to the body.

So far, there has been no related literature reporting whether PCD can increase the risk of vertebral fracture. Obviously, bone cement implantation can improve the mechanical strength and stiffness of intervertebral disc, and might increase the risk of OVCFs at the adjacent segment. $^{29-31}$ However, in this study, the procedure might have a dual role on the biomechanics of the adjacent vertebral body. On the one hand, the increase of disc stiffness might increase the risk of adjacent vertebral fracture; on the other hand, the procedure could significantly improve local kyphosis, reduce local stress concentration, and thus it might reduce the risk of clinical vertebral fracture. All cases in this study experienced osteoporosis, so prophylactic vertebroplasty was performed on the 
adjacent vertebrae to reduce the risk of fracture. Due to the limited follow-up time in our study, in the future, it is necessary to extend the follow-up time to determine the impact of this operation on adjacent vertebrae and whether prophylactic vertebroplasty is necessary.

There are some limitations in our study. First of all, the sample size of this study is small and the follow-up time is short. Therefore, a larger sample size and longer follow-up time are required to further evaluate the clinical efficacy of this surgical method. Secondly, as a retrospective study, it might need to be compared with minimally invasive surgeries, such as PKP or open surgeries like corrective osteotomy. Thirdly, the time of treatment in this study is long. Patients should stay in bed for about one week before operation, which prolongs the hospitalization days and increases the cost of treatment. Precautions must be taken to prevent complications, such as thrombosis, urinary tract infection, ileus, pneumonia, etc., caused by long-term bedridden. Last but not least, adjacent vertebral fracture is one of the most common complications after vertebroplasty. The multi-segmental vertebroplasty combined with discoplasty technique used in this study might have obvious biomechanical effects on adjacent vertebrae, which might increase the risk of vertebral fracture, and thus close followup observation is required.

\section{Conclusion}

Severe thoracolumbar OVCFs are common in clinical practice, the operation is difficult, and the incidence of complications is high. Preoperative lumbar traction and intraoperative PKP combined with PCD could effectively restore vertebral height and improve kyphosis and achieve satisfactory clinical outcomes after a short-term follow-up, which is a safe, effective, easy-to-operate and minimally invasive surgical strategy for the treatment of severe thoracolumbar OVCFs. In addition, a large sample and longterm multicenter clinical study is still needed to further clarify the effectiveness and safety of this treatment.

\section{Disclosure}

The authors report no conflicts of interest in this work.

\section{References}

1. Blondel B, Fuentes S, Metellus P, Adetchessi T, Pech-Gourg G, Dufour H. Severe thoracolumbar osteoporotic burst fractures: treatment combining open kyphoplasty and short-segment fixation. Orthop Traumatol Surg Res. 2009;95(5):359-364. PMID: 19640824. doi:10.1016/j.otsr.2009.06.001
2. Wu SS, Lachmann E, Nagler W. Current medical, rehabilitation, and surgical management of vertebral compression fractures. $J$ Womens Health. 2003;12(1):17-26. PMID: 12639365. doi:10.1089/15409990 3321154103

3. Kim DH, Vaccaro AR. Osteoporotic compression fractures of the spine; current options and considerations for treatment. Spine J. 2006;6(5):479-487. PMID: 16934715. doi:10.1016/j.spinee.20 06.04 .013

4. McLain RF. The biomechanics of long versus short fixation for thoracolumbar spine fractures. Spine. 2006;31(11Suppl):S70-S79; discussion S104. PMID: 16685240. doi:10.1097/01.brs.00002 18221.47230.dd

5. Muijs SP, Nieuwenhuijse MJ, Van Erkel AR, Dijkstra PD. Percutaneous vertebroplasty for the treatment of osteoporotic vertebral compression fractures: evaluation after 36 months. $J$ Bone Joint Surg Br. 2009;91(3):379-384. PMID: 19258616. doi:10.1302/0301620X.91B3.20970

6. Hulme PA, Krebs J, Ferguson SJ, Berlemann U. Vertebroplasty and kyphoplasty: a systematic review of 69 clinical studies. Spine. 2006;31(17):1983-2001. PMID: 16924218. doi:10.1097/01.brs.0000 $229254.89952 .6 \mathrm{~b}$

7. Li Z, Wang Y, Xu Y, Xu W, Zhu X, Chen C. Efficacy analysis of percutaneous pedicle screw fixation combined with percutaneous vertebroplasty in the treatment of osteoporotic vertebral compression fractures with kyphosis. J Orthop Surg Res. 2020;15(1):53. PMID: 32066480; PMCID: PMC7027033. doi:10.1186/s13018-020-1583-1

8. Varga PP, Jakab G, Bors IB, Lazary A, Szövérfi Z. Erfahrungen mit PMMA-zement als intervertebraler stand-alone-platzhalter. Perkutane zement-diskoplastie bei vakuumphänomen der lumbalen bandscheiben [Experiences with PMMA cement as a stand-alone intervertebral spacer. Percutaneous cement discoplasty in the case of vacuum phenomenon within lumbar intervertebral discs]. Orthopade. 2015. 44(2):124-131. German. PMID: 25715774. doi: 10.1007/s00132-015-3092-1

9. Sola C, Camino Willhuber G, Kido G, et al. Percutaneous cement discoplasty for the treatment of advanced degenerative disk disease in elderly patients. Eur Spine J. 2018. PMID: 29569159. doi:10.1007/ s00586-018-5547-7

10. Kiss L, Varga PP, Szoverfi Z, Jakab G, Eltes PE, Lazary A. Indirect foraminal decompression and improvement in the lumbar alignment after percutaneous cement discoplasty. Eur Spine J. 2019;28 (6):1441-1447. PMID: 31006068. doi:10.1007/s00586-019-05966-7

11. Yang C, Wang H, Zheng Z, et al. Halo-gravity traction in the treatment of severe spinal deformity: a systematic review and meta-analysis. Eur Spine J. 2017;26(7):1810-1816. PMID: 27858237. doi:10.1007/s00586-016-4848-y

12. Bilgilisoy Filiz M, Kiliç Z, Uçkun A, Çakir T, Koldaş Doğan Ş, Toraman NF. Mechanical traction for lumbar radicular pain: supine or prone? A randomized controlled trial. Am J Phys Med Rehabil. 2018;97(6):433-439. PMID: 29309314. doi:10.1097/PHM.000 0000000000892

13. Davies NR, Vasquez Rodriguez V, Remondino RG, et al. Inpatient versus outpatient halo-gravity traction in children with severe spinal deformity. Spine Deform. 2020;8(4):711-715. PMID: 32096139. doi:10.1007/s43390-020-00083-8

14. Hwang CJ, Kim DG, Lee CS, et al. Preoperative halo traction for severe scoliosis. Spine. 2020;45(18):E1158-E1165. PMID: 32341298. doi:10.1097/BRS.0000000000003530

15. Shimizu T, Lenke LG, Cerpa M, Lehman RA Jr, Pongmanee S, Sielatycki JA. Preoperative halo-gravity traction for treatment of severe adult kyphosis and scoliosis. Spine Deform. 2020;8 (1):85-95. PMID: 31981153. doi:10.1007/s43390-019-00017-z

16. Carlo P, Francesco C. Preoperative manual on-table-traction for the reduction of thoracolumbar burst fractures: a technical note. $J$ Craniovertebr Junction Spine. 2018;9(1):73-75. PMID: 29755241; PMCID: PMC5934969. doi:10.4103/jcvjs.JCVJS_3_18 
17. Santoro G, Ramieri A, Chiarella V, Vigliotta M, Domenicucci M. Thoraco-lumbar fractures with blunt traumatic aortic injury in adult patients: correlations and management. Eur Spine J. 2018;27 (Supp12):248-257. PMID: 29663146. doi:10.1007/s00586-018-5601-5

18. Wang F, Zhu Y. Treatment of complete fracture-dislocation of thoracolumbar spine. J Spinal Disord Tech. 2013;26(8):421-426. PMID: 22425889. doi:10.1097/BSD.0b013e31824e1223

19. Genant HK, Wu CY, van Kuijk C, Nevitt MC. Vertebral fracture assessment using a semiquantitative technique. J Bone Miner Res. 1993; 8 (9):1137-1148. PMID: 8237484. doi:10.1002/jbmr.5650080915

20. Wang S, Duan C, Yang H, Kang J, Wang Q. Percutaneous intervertebral bridging cementoplasty for adjacent multilevel osteoporotic thoracolumbar fractures with vertebral endplate-disc complex injury: technical note. Sci Rep. 2020;10(1):14354. PMID: 32873822; PMCID: PMC7462993. doi:10.1038/s41598-020-71343-w

21. Amar AP, Larsen DW, Esnaashari N, Albuquerque FC, Lavine SD, Teitelbaum GP. Percutaneous transpedicular polymethylmethacrylate vertebroplasty for the treatment of spinal compression fractures. Neurosurgery. 2001;49(5):1105-14; discussion 1114-5. PMID: 11846904.

22. Cortet B, Cotten A, Boutry N, et al. Percutaneous vertebroplasty in the treatment of osteoporotic vertebral compression fractures: an open prospective study. $J$ Rheumatol. 1999;26(10):2222-2228. PMID: 10529144.

23. Lin CC, Wen SH, Chiu CH, Chen IH, Yu TC. The clinical influence of fluid sign in treated vertebral bodies after percutaneous vertebroplasty. Radiology. 2009;251(3):866-872. PMID: 19336665. doi:10.1148/radiol.2513080914

24. Chen WJ, Kao YH, Yang SC, Yu SW, Tu YK, Chung KC. Impact of cement leakage into disks on the development of adjacent vertebral compression fractures. J Spinal Disord Tech. 2010;23(1):35-39. PMID: 20065868. doi:10.1097/BSD.0b013e3181981843
25. Fujiwara T, Akeda K, Yamada J, Kondo T, Sudo A. Endplate and intervertebral disc injuries in acute and single level osteoporotic vertebral fractures: is there any association with the process of bone healing? BMC Musculoskelet Disord. 2019;20(1):336. PMID 31324243; PMCID: PMC6642561. doi:10.1186/s12891-019-2719-5

26. Ortiz AO, Bordia R. Injury to the vertebral endplate-disk complex associated with osteoporotic vertebral compression fractures. AJNR Am J Neuroradiol. 2011;32(1):115-120. PMID: 20801764; PMCID: PMC7964944. doi:10.3174/ajnr.A2223

27. Chin DK, Kim YS, Cho YE, Shin JJ. Efficacy of postural reduction in osteoporotic vertebral compression fractures followed by percutaneous vertebroplasty. Neurosurgery. 2006;58(4):695-700; discussion 695-700. PMID: 16575333. doi:10.1227/01.NEU.0000204313.3 6531.79

28. Schmidt R, Cakir B, Mattes T, Wegener M, Puhl W, Richter M. Cement leakage during vertebroplasty: an underestimated problem? Eur Spine J. 2005;14(5):466-473. PMID: 15690210; PMCID: PMC3454665. doi:10.1007/s00586-004-0839-5

29. Lin EP, Ekholm S, Hiwatashi A, Westesson PL. Vertebroplasty: cement leakage into the disc increases the risk of new fracture of adjacent vertebral body. AJNR Am J Neuroradiol. 2004;25 (2):175-180. PMID: 14970015.

30. Polikeit A, Nolte LP, Ferguson SJ. The effect of cement augmentation on the load transfer in an osteoporotic functional spinal unit: finite-element analysis. Spine. 2003;28(10):991-996. PMID: 12768136. doi:10.1097/01.BRS.0000061987.71624.17

31. Baroud G, Nemes J, Heini P, Steffen T. Load shift of the intervertebral disc after a vertebroplasty: a finite-element study. Eur Spine J. 2003;12(4):421-426. PMID: 12687437; PMCID: PMC3467784. doi: $10.1007 / \mathrm{s} 00586-002-0512-9$
International Journal of General Medicine

\section{Publish your work in this journal}

The International Journal of General Medicine is an international, peer-reviewed open-access journal that focuses on general and internal medicine, pathogenesis, epidemiology, diagnosis, monitoring and treatment protocols. The journal is characterized by the rapid reporting of reviews, original research and clinical studies across all disease areas. The manuscript management system is completely online and includes a very quick and fair peer-review system, which is all easy to use. Visit http://www.dovepress.com/ testimonials.php to read real quotes from published authors. 